\title{
Avaliação da Organização Logística em Empresas da Cadeia de Suprimento de Alimentos: Indústria e Comércio
}

\author{
César Roberto Lavalle da Silva \\ Paulo Fernando Fleury
}

\section{RESUMO}

O objetivo deste artigo é avaliar o estágio de desenvolvimento da organização logística de empresas industriais e comerciais, pertencentes à cadeia de suprimento do setor alimentício. A utilização do modelo analítico desenvolvido por Bowersox e Daugherty (1992), e adaptado por Lavalle (1995), permitiu comparar o segmento industrial e comercial desta cadeia de suprimento, no que diz respeito ao grau de sofisticação da organização logística. A análise dos dados obtidos por meio de pesquisa de campo indica que, relativamente às empresas comerciais, as empresas industriais tendem a ter operações logísticas mais complexas; como conseqüência, buscam maior nível de flexibilidade operacional. Segundo o modelo adotado, o nível de flexibilidade, por sua vez, está diretamente relacionado ao nível de sofisticação da organização logística.

Palavras-chaves: logística empresarial; gerenciamento da cadeia de suprimento; organização logística.

\begin{abstract}
The objective of this paper is to present a study on the stage of development of logistic organization on the commercial and industrial companies belonging to Brazilian supply chain in food industry. The industrial and commercial companies were compared in relation to the degree of sophistication of their logistic organization, based on a model developed by Bowersox and Daugherty (1992), and adapted by Lavalle (1995). The results, based on field research, indicate that industrial companies have a higher level of operational complexity than commercial companies, and as a consequence they seek higher flexibility on their operations by means of a more sophisticated logistic organization.
\end{abstract}

Key words: logistics; supply chain management; logistic organization. 


\section{INTRODUÇÃO}

A cadeia de suprimento do setor alimentício tem experimentado mudanças significativas na última década, em função, principalmente, do aumento da competição imposta pela combinação da abertura comercial com a estabilização econômica. Se, por um lado, a estabilização econômica reduziu drasticamente as possibilidades de ganhos inflacionários, forçando as empresas a focar nas atividades fins do negócio, por outro lado, a maior disponibilidade de produtos similares, com a chegada dos importados, aumentou ainda mais a competição no mercado.

De forma geral, as empresas têm reagido a estes movimentos por meio de uma série de mudanças, tanto nos aspectos gerenciais quanto operacionais. Uma das mudanças que pode ser facilmente observada é a busca de relacionamentos mais próximos entre as empresas industriais e comerciais, mediante um esforço de coordenação das operações logísticas. Esta é uma das razões pelas quais as questões logísticas têm crescido de importância na agenda da alta administração. A integração da cadeia de suprimento passou a ser vista como uma das maiores oportunidades para a obtenção de ganhos de produtividade no âmbito das empresas.

\section{Figura 1: Evolução do Serviço de Distribuição Física na Decisão de} Compra do Comércio

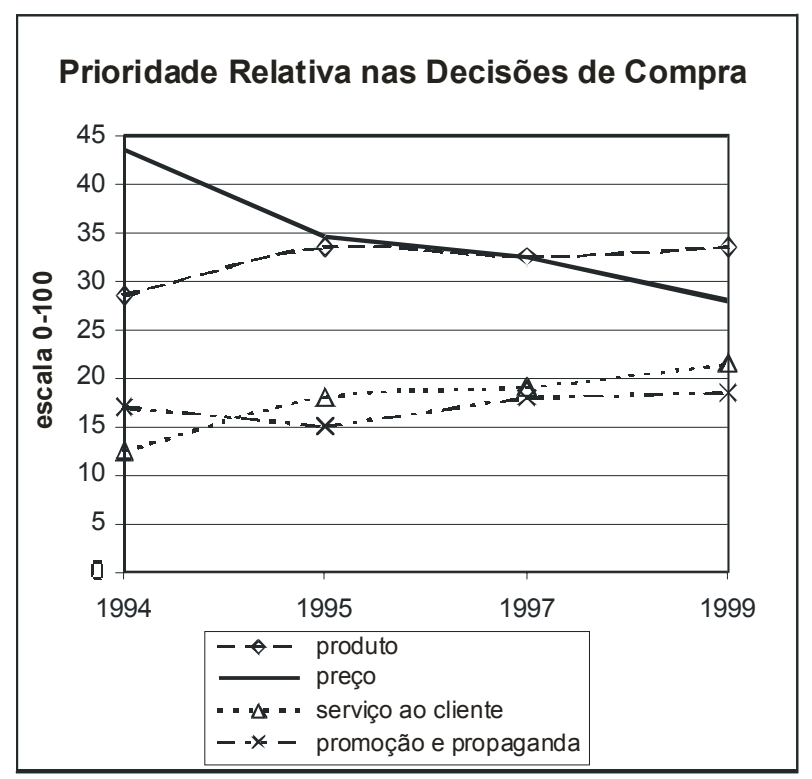


A Figura 1 apresenta resultado de pesquisa desenvolvida pelo Centro de Estudos em Logística do Instituto de Pós-Graduação e Pesquisa em Administração da Universidade Federal do Rio de Janeiro - CEL/COPPEAD/UFRJ (Fleury e Lavalle, 1997; Lavalle, 1998), que aponta para a importância crescente do serviço de distribuição física no processo decisório das empresas comerciais na escolha de fornecedores industriais de bens de consumo não duráveis. As negociações comerciais, tradicionalmente centradas em preço, passam a considerar o serviço de distribuição como importante fator de diferenciação nas decisões de compra por parte do comércio.

A valorização da logística na estratégia empresarial gera, como conseqüência, uma série de perguntas relacionadas à forma como as empresas de uma mesma cadeia de suprimento estão se organizando para enfrentar os novos desafios. Segundo Bowersox e Closs (1996), o entendimento do processo de desenvolvimento organizacional das empresas pode ser de grande utilidade para os executivos de logística. Este artigo se propõe apresentar evidências sobre o grau de desenvolvimento das organizações logísticas de conjuntos de empresas, que se relacionam dentro de uma dada cadeia de suprimento (vide Figura 2). O elo produção/comercialização de alimentos foi escolhido por representar diversos segmentos (indústria, varejo e atacado) da economia brasileira com alto grau de dinamismo e que, como conseqüência, vêm desenvolvendo grande esforço no aprimoramento operacional e gerencial das atividades logísticas. Uma expressiva evidência desse dinamismo é o Movimento ECR Brasil (Efficient Consumer Response - Resposta Rápida ao Consumidor), que em novembro de 1998 (ECR, 1998), organizou seu primeiro congresso, durante o qual foram apresentados resultados já alcançados por empresas que aderiram aos programas que visam a maior eficiência da cadeia de suprimento.

\section{Figura 2: A Cadeia de Suprimento do Setor de Alimentos e Bebidas}

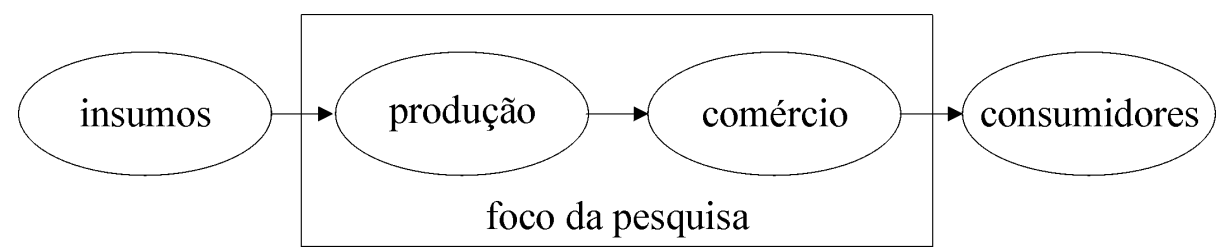

Vale ressaltar que a entrada de novos competidores internacionais, com alta capacitação logística, tem contribuído ainda mais para a aceleração das mudanças acima mencionadas, e deve ser encarada como fator determinante para a reflexão e recolocação do setor em estudo.

O elo produção/comercialização do setor alimentício vem passando por mudanças substanciais, com a introdução de novas tecnologias de informação e comunicação, 
e de abordagens gerenciais voltadas ao processo logístico, capazes de gerar impactos profundos na forma atual de fazer negócios. Cada vez mais, a busca por eficiência tem como pré-requisito a alta qualidade dos serviços prestados ao cliente final; no entanto, para atingir plenamente estes objetivos, é fundamental que exista alto nível de integração e coordenação entre os processos logísticos de empresas de uma mesma cadeia de suprimento. As empresas cada vez mais estão se conscientizando de que não é possível atender as exigências de serviço dos clientes e, simultaneamente, cumprir com os objetivos de custo da empresa, sem trabalhar de forma coordenada com outros participantes da cadeia de suprimento. As empresas não trabalham no vácuo. Ações de uma empresa afetam de forma positiva ou negativa os custos das outras empresas da cadeia de suprimento.

Nos Estados Unidos, os últimos anos têm-se caracterizado por fortes movimentos de integração nas cadeias de suprimentos, como por exemplo, o ECR, e o Quick Response. Verifica-se ali que as empresas de vanguarda vêm utilizando-se da logística como importante fonte de capacitação na implementação de suas estratégias competitivas (Stalk, Evans e Schulman, 1992). O sucesso na implementação de programas de integração está diretamente relacionado à capacidade das empresas de desempenhar atividades conjuntas e compartilhar informações. Estas empresas necessitam dispor de uma organização logística bem desenvolvida. Além disso, é importante que estruturas de diferentes empresas de uma mesma cadeia de suprimento sejam compatíveis entre si. Neste sentido, é importante considerar as diferenças entre os sistemas logísticos da indústria e do comércio.

De maneira geral, as empresas industriais se caracterizam por processos produtivos e logísticos de maior complexidade do que as do comércio. Nestes casos é bastante comum observar uma cadeia produtiva com vários estágios escalonados, como é o caso, por exemplo, do setor de alimentos de massas. Neste setor, o processo logístico vai desde o plantio e a colheita de grãos, passando por processamentos intermediários, até o estágio de industrialização final e entrega aos estabelecimentos comerciais. No caso do comércio, a complexidade é significativamente menor, já que lida, basicamente, com a distribuição de produtos acabados. Por outro lado, o processo logístico do comércio se caracteriza por sua grande amplitude devido às múltiplas transações associadas ao grande número de itens comercializados, se comparado a indústria. Estas diferenças, quando não são devidamente consideradas, podem ser fontes de obstáculos para os movimentos de integração da cadeia de suprimento.

A próxima seção apresenta o modelo conceitual, que serviu de referência para verificar o estágio de desenvolvimento da organização logística em empresas comerciais e industriais pertencentes à cadeia de alimentos. Em seguida, são analisados os resultados da pesquisa à luz do modelo utilizado. 


\section{O Modelo Conceitual}

O modelo conceitual utilizado nesta pesquisa (Lavalle, 1995), apresentado na Figura 3, é uma adaptação do modelo desenvolvido por Bowersox e Daugherty (1992), o qual foi baseado em ampla pesquisa denominada Leading Edge Logistics, feita no mercado norte-americano, em 1989 (Bowersox et al., 1989).

\section{Figura 3: O Modelo Conceitual}

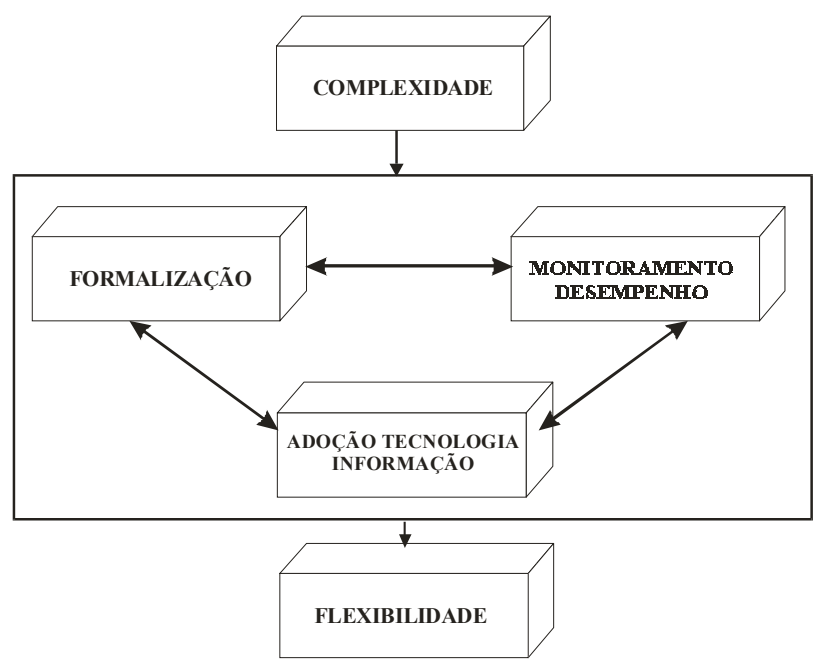

Segundo o modelo conceitual, empresas de vanguarda se destacam pelo alto nível de flexibilidade em seu sistema logístico, visando ao atendimento de exigências de clientes-chaves e situações contingenciais. Ainda assim, a capacidade de ser flexível é resultante do nível de sofisticação da organização logística, que pode ser decomposta em três dimensões: formalização, monitoramento de desempenho $\mathrm{e}$ adoção de tecnologia de informação. Por fim, o nível de sofisticação necessário para a organização logística, está diretamente relacionado ao nível de complexidade das atividades logísticas das empresas consideradas.

A formalização refere-se à forma de organização das funções logísticas nos aspectos de coordenação, autoridade e planejamento. O monitoramento de desempenho é a dimensão que trata da sistemática de controle dos processos logísticos, peça-chave para o seu aperfeiçoamento contínuo. A adoção de tecnologia está associada à intensidade de uso de softwares e hardwares em processos logísticos, a qual viabiliza a manipulação e a transmissão de grandes quantidades 
de informações operacionais e gerenciais precisas e em tempo hábil que, por seu turno, possibilita a maior agilidade do processo decisório. A flexibilidade reflete a capacitação das empresas em identificar as necessidades e oportunidades de mercado de forma inovadora e orientada ao cliente e responder proficientemente a seu desiderato. Finalmente, a complexidade operacional, segundo Van Amstel e Starreveld (1993), está relacionada às características do negócio, tais como: número de clientes, fornecedores, instalações físicas e unidades de manutenção de estoque (stock keeping units - SKU's).

A formalização da estrutura logística de modo integrado possibilita a orquestração plena do processo rotineiro, liberando a alta administração a dedicar-se às questões estratégicas e a mobilizar esforços logísticos em situações extemporâneas com grande precisão. A responsabilidade fundamental da alta administração é criar um ambiente organizacional dentro do qual o executivo operacional tem as melhores condições para atingir os objetivos corporativos. Neste sentido, a estrutura organizacional tem papel vital na arte de gerenciar. Tradicionalmente, a responsabilidade pela gerência dos processos logísticos tem sido fragmentada, gerando vulnerabilidades em função de duplicação de esforços, desperdícios de recursos, conflitos de autoridade e incompatibilidade de objetivos.

A adoção de tecnologia adequada, ao viabilizar a disponibilização de informações precisas e em tempo hábil, permite uma avaliação mais realista da situação que conseqüentemente minimiza o tempo de resposta e aumenta a possibilidade de sucesso da empresa. O processo decisório se torna mais ágil; os ciclos operacionais mais curtos; as adaptações no sistema menos traumáticas.

O monitoramento permanente do desempenho dos processos logísticos torna-os mais estáveis. A análise sistemática de indicadores associados a custos, serviços ao cliente e qualidade do produto resulta em maior conhecimento do processo como um todo que, por seu turno, possibilita maior flexibilidade das operações. A prática de benchmarking parte do princípio de que não existe razão para se reinventar a roda; observar como outras organizações fazem atividades semelhantes, ou tratam situações adversas, pode significar economia de tempo e recursos.

A empresa que dispõe de flexibilidade em suas operações pode beneficiar-se em situações especiais, seja pela maior habilidade de satisfazer o cliente, seja pela capacidade de desempenhá-las com custo menor. A idéia central é manter-se criativo, tirando proveito das alternâncias do mercado. Uma empresa com operações flexíveis é capaz de customizar seus serviços e capitalizar seus esforços nas oportunidades mais lucrativas. Em alguns casos, a flexibilidade logística pode ser usada para tirar proveito de flutuações de demanda, em outros para responder positivamente a demandas peculiares de clientes-chaves. Independentemente das razões, 
desempenho superior está relacionado a habilidade de a empresa identificar as oportunidades do mercado e responder-lhes proficientemente.

Os resultados da presente pesquisa possibilitaram verificar o modelo analítico proposto por Lavalle (1995): ele relaciona a complexidade logística com o nível de sofisticação da organização logística e a flexibilidade das empresas, ou seja, a análise dos resultados visa a responder às seguintes perguntas de pesquisa:

. Como as empresas industriais e comerciais do setor de alimentos e bebidas estão estruturando a organização dos seus sistemas logísticos?

. Existe um padrão no desenvolvimento da organização logística, considerando o comércio e a indústria do setor de alimentos e bebidas?

. Existe um pólo irradiador de adoção de tecnologia entre a indústria e o comércio?

- Quais as perspectivas de desenvolvimento da organização logística nas empresas pertencentes à cadeia de suprimento de alimentos e bebidas?

\section{A Pesquisa de Campo e as Principais Características da Amostra}

A pesquisa foi feita por meio de questionário estruturado, por meio do qual foi avaliada uma série de questões relacionadas às dimensões do modelo conceitual. As perguntas eram basicamente de natureza qualitativa, para as quais foram utilizadas escalas Likert.

As empresas primeiramente agruparam-se segundo sua natureza e, em seguida, foram apurados os resultados para as variáveis que compõem cada dimensão do modelo conceitual. Por exemplo, no caso da dimensão complexidade operacional, foram consideradas as variáveis: número de SKU's, número de fornecedores, número de armazéns, número de clientes, o nível de perecibilidade dos produtos e a existência de instalações de manufatura.

A coleta de dados foi realizada em 26 empresas do setor de alimentos e bebidas, entre abril de 1996 e junho de 1997. Em geral, as empresas industriais caracterizam-se por serem maiores do que as empresas comerciais: o faturamento das 15 empresas industriais pesquisadas, medido pela mediana, era de $\mathrm{R} \$ 435$ milhões, com 2.757 empregados; no caso das 11 empresas comerciais, este faturamento era de $\mathrm{R} \$ 300$ milhões, com 1.675 empregados. 
Por se tratar, em geral, de grandes empresas, líderes em seus respectivos setores, espera-se que a amostra reflita o estágio de desenvolvimento da organização logística de empresas que, em algum grau, percebem a importância da logística para o sucesso do negócio. Neste sentido, por se tratar de empresas de êxito, as conclusões deste trabalho devem refletir o padrão de desenvolvimento da organização logística de empresas comerciais e industriais.

\section{Quanto à Avaliaçāo da Complexidade logistica}

A análise a seguir visa a estabelecer, comparativamente, o nível de complexidade logística entre as empresas comerciais e industriais pesquisadas.

O Quadro 1 apresenta o resultado final para a dimensão complexidade operacional, em que se verifica que as empresas industriais são, em geral, logisticamente mais complexas do que as empresas comerciais. Se, por um lado, as empresas comerciais geralmente apresentam maior número de fornecedores e de SKU's em seus estoques, as industriais, com suas fábricas, servem uma base maior de clientes, com mais produtos perecíveis, através de um maior número de armazéns. É importante ressaltar que a indústria, ao contrário do comércio, tem complexa logística de apoio à manufatura, a qual faz fronteira entre o processo de suprimento e o processo de distribuição.

\section{Quadro 1: Complexidade Operacional : Comércio versus Indústria}

\begin{tabular}{|c|c|c|}
\hline Complexidade & Comércio & Indústria \\
\hline Nível & - & + \\
\hline Número de fornecedores & 650 & 246 \\
\hline Número SKU & 6000 & 160 \\
\hline Número de armazéns & 1 & 6 \\
\hline Número de clientes/lojas & 110 & 7000 \\
\hline Existência de fábricas & não & $\operatorname{sim}$ \\
\hline Perecibilidade* & $39 \%$ & $58 \%$ \\
\hline
\end{tabular}

Segundo o modelo adotado, espera-se, portanto, que as empresas industriais, comparativamente às empresas comerciais, busquem desenvolver maior nível de flexibilidade em seus sistemas logísticos, para fazer frente à maior complexidade operacional, mediante organização logística mais sofisticada. 


\section{Quanto à Avaliação da Flexiblididade logística}

Esta seção busca avaliar a importância atribuída pelas empresas comerciais e industriais à flexibilidade de seus sistemas logísticos. Importa ressaltar que, segundo o modelo conceitual adotado, esta é a dimensão que melhor caracteriza as empresas de vanguarda em logística. A dimensão flexibilidade foi avaliada segundo o nível desejado e o nível real. A Figura 4 indica que os itens de flexibilidade podem ser tanto de cunho operacional, como a crise de oferta no suprimento e a falha do sistema de computação, quanto estratégico, ou seja, relacionado à capacidade de a empresa atender as especificidades de segmentos ou clientes, como por exemplo, a customização do nível de serviço e o atendimento de condições especiais de embalagem e faixa horária de recebimento do pedido.

\section{Figura 4: Itens de Flexibilidade dos Sistemas Logísticos}

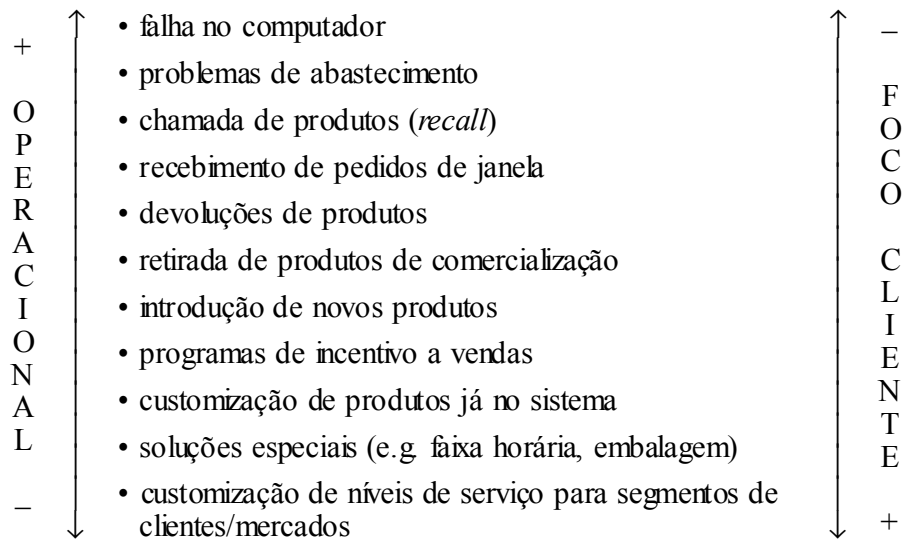

Segundo o Quadro 2, as empresas industriais, além de serem mais flexíveis, também desejam nível de flexibilidade superior quando comparadas às empresas comerciais.

\section{Quadro 2: Flexibilidade Desejada e Real: Comércio versus Indústria}

\begin{tabular}{|lcc|}
\hline Flexibilidade & Comércio & Indús tria \\
Desejada & 3,6 & 4,1 \\
Real & 3,0 & 3,5 \\
\hline
\end{tabular}

escala: 1 - baixa; 5 - alta. 
É importante enfatizar que flexibilidade logística busca o estabelecimento de planos de contingência, voltados para a manutenção das operações em situações extemporâneas. Por outro lado, busca-se também desenvolver a habilidade de se promover o atendimento diferenciado a clientes-chaves; no entanto, o que caracteriza um nível adequado de sofisticação da organização logística é a capacidade de obter flexibilidade com alto nível de eficiência. Neste sentido, verifica-se que as empresas de ambos os setores estão interessadas em aumentar a flexibilidade de seus sistemas logísticos, visando ao atendimento mais focado nas exigências dos clientes.

Em suma, conforme era de se esperar, as empresas industriais, por experimentarem maior nível de complexidade em suas operações, desenvolveram sistemas logísticos mais flexíveis do que as empresas comerciais, para fazer frente aos desafios relacionados tanto à manutenção do fluxo físico quanto àqueles voltados às necessidades de diferenciação mercadológica.

\section{Quanto à Avaliação da Sofisticação da Organizaçāo logistica}

A seguir, pretende-se comparar o nível de sofisticação da organização logística do comércio com o nível de sofisticação da indústria. O nível de sofisticação da organização logística foi obtido a partir da resultante das dimensões formalização, monitoramento de desempenho e adoção de tecnologia, segundo o modelo conceitual adotado.

. Nível de formalização. A dimensão formalização foi apurada a partir de duas varáveis: o nível de controle, atribuído às unidades responsáveis pela logística sobre os componentes logísticos, e o nível de estruturação organizacional formalizada, obtido em função da posição hierárquica do principal executivo da logística, do nível de participação em decisões estratégicas e da existência de missão e de planejamento logísticos.

O Quadro 3 indica que em 50\% das empresas comerciais, o principal executivo da logística está localizado no primeiro escalão da estrutura organizacional, ou seja, responde diretamente ao presidente, enquanto na indústria isto foi verificado em apenas $29 \%$ dos casos. Com relação ao nível de participação nas decisões estratégicas, o principal executivo da logística tem participação direta em $80 \%$ das empresas comerciais e em $71 \%$ das empresas industriais. Por outro lado, o percentual de empresas com planejamento logístico formalizado é similar para os dois conjuntos de empresas. As empresas industriais só se destacam com relação às comerciais no que se refere à existência de missão logística: no cômputo geral, 
as empresas comerciais desenvolvem um nível de estruturação organizacional formalizada da logística superior às empresas industriais.

\section{Quadro 3: Nível de Estruturação Organizacional Formalizada: Comércio versus Indústria}

\begin{tabular}{|lcc|}
\hline Estrutura Org. Formal & Comércio & Indús tria \\
nível hierárquic o ( $1^{\circ}$ escalão) & $50 \%$ & $29 \%$ \\
nível de particip ação & $80 \%$ & $71 \%$ \\
planejamento & $36 \%$ & $33 \%$ \\
missão & $50 \%$ & $60 \%$ \\
\hline
\end{tabular}

Segundo o Quadro 4 o nível de controle da unidade funcional da logística sobre os componentes logísticos é maior nas empresas industriais do que nas comerciais. Este quadro apresenta o percentual de empresas da amostra que detêm controle total, parcial ou nenhum sobre os componentes logísticos. Quanto ao nível de controle total, exercido pela estrutura funcional responsável pela logística, verifica-se que não existem diferenças significativas entre os dois conjuntos de empresas, mas observa-se que existe maior percentual de empresas industriais com controle parcial sobre os componentes logísticos do que o percentual das comerciais. Outra questão interessante é que o comércio concentra seu controle nas atividades de armazenagem e transporte, enquanto na indústria o controle sobre as atividades logísticas é mais homogêneo.

\section{Quadro 4: Nível de Controle sobre os Componentes Logísticos: Comércio versus Indústria}

\begin{tabular}{|lcccccc|}
\hline \multirow{2}{*}{ Componentes Logísticos } & \multicolumn{3}{c}{ Comércio (\%) } & \multicolumn{3}{c|}{ Indús tria (\%) } \\
& não há & parcial & total & não há & parcial & total \\
compras/planejamento da produção & 30,0 & 40,0 & 30,0 & 20,0 & 26,7 & 53,3 \\
processamento de pedidos & 10,0 & 40,0 & 50,0 & 13,3 & 33,3 & 53,3 \\
estoque & 10,0 & 40,0 & 50,0 & 6,7 & 33,3 & 60,0 \\
transporte & 10,0 & 20,0 & 70,0 & 0,0 & 46,7 & 53,3 \\
armazenagem & 10,0 & 10,0 & 80,0 & 6,7 & 33,3 & 60,0 \\
serviço ao cliente & 20,0 & 60,0 & 20,0 & 13,3 & 73,3 & 13,3 \\
MÉDIA & $\mathbf{1 5 , 0}$ & $\mathbf{3 5 , 0}$ & $\mathbf{5 0 , 0}$ & $\mathbf{1 0 , 0}$ & $\mathbf{4 1 , 1}$ & $\mathbf{4 8 , 9}$ \\
\hline
\end{tabular}

Em suma, tanto as empresas comercias quanto as industriais apresentam nível semelhante de formalização da logística. 
. Nível de monitoramento de desempenho. A dimensão de monitoramento de desempenho foi avaliada segundo o nível médio de insatisfação com o sistema de indicadores apresentado no Quadro 5, a seguir. Os resultados indicam que o nível de insatisfação com o sistema de monitoramento de desempenho é de aproximadamente $30 \%$, tanto para o caso do comércio quanto para a indústria.

Altos níveis de insatisfação estão associados a todas as classes de indicadores, sendo que o comércio percebe as maiores carências no benchmarking e qualidade, enquanto a indústria aponta benchmarking e o serviço ao cliente. É interessante observar que estas classes de indicadores estão mais voltadas à interface das empresas, enquanto as demais se referem à mensuração tradicional de desempenho de recursos, utilizados pelas empresas. Estes dados refletem uma preocupação maior com os aspectos relacionados à cadeia de suprimento como um todo: o gerenciamento das atividades logísticas ganha abordagem mais ampla ao incluir, na agenda dos executivos, a busca por melhores práticas e a orientação ao cliente.

\section{Quadro 5: Nível de Insatisfação com o Monitoramento de Desempenho: Comércio versus Indústria}

\begin{tabular}{|c|c|c|}
\hline \multirow{2}{*}{ Classes de Indicadores } & \multicolumn{2}{|c|}{ Nível de Ins atis fação (\%) } \\
\hline & Comércio & Indús tria \\
\hline benchmarking & 37,1 & 37,3 \\
\hline qualidade & 32,4 & 22,4 \\
\hline custos & 29,5 & 32,8 \\
\hline ativo & 29,5 & 27,2 \\
\hline produtividade & 25,1 & 26,1 \\
\hline serviço ao cliente & 24,7 & 35,5 \\
\hline MÉDIA & 29,7 & 30,2 \\
\hline
\end{tabular}

. Nível de adoção de tecnologia de informação. A dimensão tecnologia de informação foi avaliada com base em seis medidas, as quais estão apresentadas no Quadro 6.

Com relação à utilização de troca eletrônica de dados (electronic data interchangeEDI), o número de aplicações nas empresas industriais é $60 \%$ superior ao das empresas comerciais, indicando maior nível de adoção de tecnologia por parte das empresas industriais. 


\section{Quadro 6: Nível de Insatisfação com o Monitoramento de Desempenho: Comércio versus Indústria}

\begin{tabular}{|lcc|}
\hline Tecnologia & Comércio & Indús tria \\
Nível & - & + \\
número de softwares & 23 & 27 \\
insatisfação com os softwares & $41 \%$ & $43 \%$ \\
insatisfação com a qualidade da informação & $32 \%$ & $33 \%$ \\
insatisfação com o processo de implementação de softwares & $33 \%$ & $35 \%$ \\
insatisfação com o hardware operacional & $48 \%$ & $47 \%$ \\
insatisfação com o hardware computacional & $41 \%$ & $40 \%$ \\
nível de utilização de EDI & $0,9 /$ empresa & $1,6 /$ empresa \\
\hline
\end{tabular}

Não foram encontradas diferenças significativas entre os grupos de empresas pesquisadas, ao avaliarem-se as demais variáveis da dimensão adoção de tecnologia; no entanto, vale ressaltar que, com relação aos softwares, o nível de insatisfação com relação às áreas de aplicação, à qualidade da informação disponível e ao processo de implementação é bastante alto, ou seja, entre $32 \%$ e $43 \%$.

Apesar do nível semelhante de insatisfação entre as empresas comerciais e industriais, as empresa comerciais apresentam, em média, 23 áreas de aplicativos com softwares instalados, enquanto para as empresas industriais este número sobe para 27. No que tange aos hardwares operacionais e computacionais pesquisados, apesar de também não se verificarem diferenças significativas entre os segmentos pesquisados, os níveis de insatisfação são muito altos, cerca de $48 \%$ e $40 \%$, respectivamente. Os hardwares operacionais e computacionais considerados se relacionam com as etapas de captação, comunicação e distribuição de informações, as quais são inputs, ou outputs dos softwares instalados.

. Conclusão a respeito de tecnologias de informação. A análise geral dos resultados indica alto grau de insatisfação com o fluxo de informações logísticas nas empresas pesquisadas, geradas a partir de hardwares operacionais e computacionais, assim como softwares. Esses níveis de insatisfação são coerentes com os níveis encontrados na dimensão monitoramento de desempenho, já que os sistemas indicadores são outputs dos fluxos de informação gerados por softwares e hardwares.

Neste sentido, é importante considerar que existem vários obstáculos, internos e externos às empresas, que dificultam o processo de adoção de novas tecnologias e contribuem para os altos níveis de insatisfação observados. A pesquisa identificou que a inexistência de figuras-chaves nas empresas, que patrocinem a adoção de novas tecnologias, e a demora na solução de problemas estão entre os mais impor- 
tantes obstáculos, tanto para o comércio quanto para a indústria. No caso da indústria, a incompatibilidade com sistemas já existentes aparece como o principal obstáculo para a adoção de novas tecnologias de informação. Este fato evidencia a maior tradição no uso de tecnologias de informação por parte das empresas industriais.

\section{Aderéncia ao Modelo Conceitual Adotado}

Os resultados de pesquisa também possibilitaram outras análises mais agregadas, visando a estabelecer uma comparação entre as empresas comerciais e industriais, à luz do modelo conceitual proposto. Esta análise foi feita a partir de matrizes $2 \times 2$, as quais procuram relacionar complexidade operacional, flexibilidade desejada e real, e sofisticação da organização dos sistemas logísticos. A sofisticação da organização logística resulta das dimensões formalização, monitoramento de desempenho e adoção de tecnologia. Esta seção tem como objetivo avaliar, de forma esquemática, o nível de consistência geral dos resultados de pesquisa em face do modelo conceitual adotado.

As Figuras 5 e 6 apresentam as matrizes $2 \times 2$ com os resultados agregados, considerando o conjunto de empresas comerciais e o conjunto de empresas industriais, os quais relacionam a complexidade operacional à flexibilidade real e desejada do sistema logístico. Observa-se, em primeiro lugar, que as empresas industriais têm, em geral, operações logísticas mais complexas do que as comerciais, e também apresentam e desejam maior flexibilidade logística: quanto maior o nível de complexidade operacional, maior a necessidade de flexibilidade logística.

Figura 5: Complexidade Operacional versus Flexibilidade Real

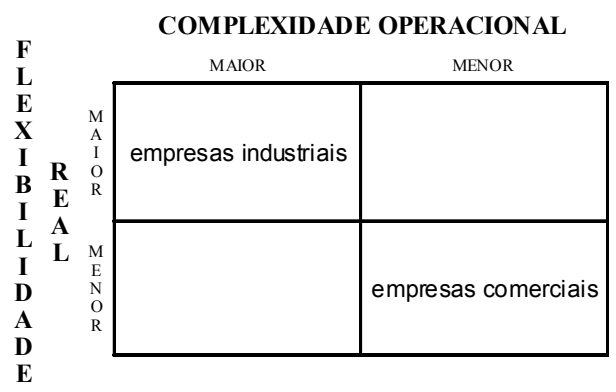




\section{Figura 6: Complexidade Operacional versus Flexibilidade Desejada}

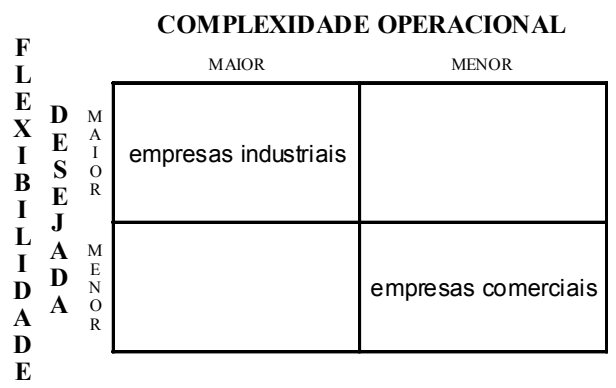

A Figura 7 relaciona a complexidade operacional com o nível de sofisticação da organização logística nas empresas, isto é, as empresas industriais, mais complexas operacionalmente, apresentam nível de sofisticação superior às empresas comerciais. O maior nível de sofisticação da organização logística da indústria é devido ao maior nível de adoção de tecnologia de informação. E, conforme já se ressaltou, o comércio detém o maior poder de barganha na cadeia de suprimento e constitui um fator importante para a introdução de tecnologia por parte da indústria: a evolução da organização logística em empresas industriais pode estar sendo impulsionada, em grande medida, por exigências do comércio.

\section{Figura 7: Complexidade Operacional versus Sofisticação}

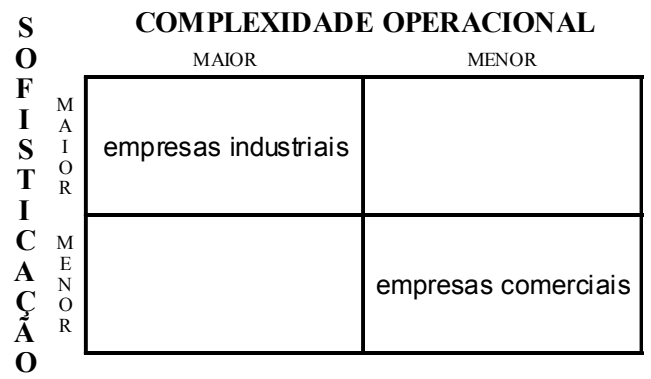

Os resultados indicam que a indústria tende a desenvolver um nível de sofisticação da organização logística superior ao comércio. Segundo a Figura 8, o modelo se confirma a partir da constatação de que maior nível de sofisticação da organização logística está diretamente relacionado ao nível de flexibilidade do sistema logístico. Neste sentido, o gap de flexibilidade, ou seja a diferença entre flexibilidade desejada e real, tem grandes chances de ser reduzido a partir de maiores investimentos em tecnologias de informação, que possibilitam melhor monitoramento de desempenho e proporcionam, conseqüentemente, maior formalização e controle da organização logística. 


\section{Figura 8: Sofisticação versus Flexibilidade Real}

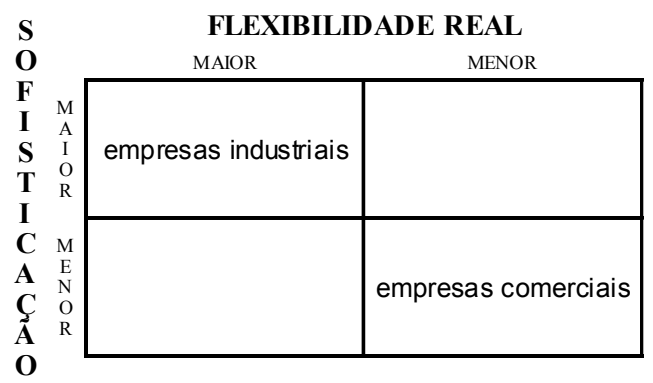

Em suma, os resultados apontam para uma série de oportunidades em termos de tecnologias de informação, visando ao aperfeiçoamento do sistema logístico das empresas; no entanto é importante frisar que o sucesso das mudanças está diretamente relacionado a uma abordagem sistêmica com relação às dimensões que resultam na capacitação logística nas empresas. Por exemplo, os efeitos positivos advindos de uma nova tecnologia de informação terão melhores chances de materialização quanto mais bem estruturada estiver a área de logística dentro da organização da empresa, seja do ponto de vista funcional, seja pela existência de sistemas de indicadores abrangentes. A existência de dificuldades para a introdução de novas tecnologias de informação, conforme se observa na pesquisa, pode ter sua raiz no fato de não haver equilíbrio entre as dimensões que caracterizam o nível de organização logística das empresas, quais sejam: formalização, monitoramento de desempenho e adoção de tecnologia.

Como constatação final sobre a robustez do modelo conceitual testado nesta pesquisa, o Quadro 7 revela o melhor desempenho logístico da indústria, quando comparado ao comércio.

\section{Quadro 7: Nível de Desempenho Logístico: Comércio versus Indústria}

\begin{tabular}{|lcc|}
\hline Indicadores de Desempenho & Comércio & Indús tria \\
atraso na entrega & $10 \%$ & $5 \%$ \\
quantidade entregue do total pedido & $90 \%$ & $95 \%$ \\
erro na documentação & $3 \%$ & $0,2 \%$ \\
avarias & $2,5 \%$ & $0,5 \%$ \\
\hline
\end{tabular}

Estes resultados são consistentes com as conclusões que apontam a indústria como tendo organização logística superior ao comércio. 


\section{Perspectivas para as Empresas Comercials e Industriais}

A seguir, serão apresentadas as tendências de evolução da organização logística em empresas comerciais e industriais, delineadas a partir de informações acessórias coletadas na pesquisa.

- A importância do serviço de distribuição nas decisões de compra do comércio continuará em ascensão nos próximos anos. Esta tendência consiste em importante força propulsora de mudanças futuras, no sentido upstream, da cadeia de suprimento de alimentos. Como resultado desta força motriz, a estrutura das organizações logísticas nas empresas de vanguarda se apresentará mais aberta ao relacionamento estável ao longo da cadeia, permitindo maiores avanços gerenciais e operacionais. $\mathrm{O}$ foco dos executivos estará concentrado na busca por produtividade, mantendo altos níveis de serviço, em megaprocessos que transcendem as fronteiras tradicionais das empresas. Neste sentido, crescerá o nível de utilização de tecnologia de informação para dar suporte ao esforço de integração de processos.

. O poder de barganha na cadeia de suprimento de alimentos tende a se consolidar junto às grandes redes de varejo. Como conseqüência, aumentará a necessidade de desenvolvimento de mecanismos, por parte da indústria, para melhor conhecer as exigências de serviços de distribuição física, assim como o desempenho percebido pelo comércio. É importante frisar que a satisfação do cliente é resultante da comparação entre expectativas e percepções de desempenho, sendo que as exigências estão em movimento crescente; portanto manter-se competitivo significa obter algo a mais do que alto desempenho operacional. Implica o desenvolvimento de uma organização logística sensível à dinâmica do mercado, capaz de responder aos desafios por meio de estrutura altamente flexível.

. Percebe-se forte movimento no comércio no que diz respeito ao aperfeiçoamento da organização logística. Esta tendência resultará em pressão, ao longo de toda a cadeia, por maior eficiência. As grandes redes de varejo demandarão maior foco em suas operações, o que aumentará a necessidade de segmentação logística por parte da indústria, com vista à customização dos níveis de serviços prestados. Para atender a crescente diversidade de pacotes de serviços de distribuição, a indústria deverá buscar maior grau de flexibilidade mediante maior sofisticação da organização do sistema logístico. Neste sentido, as deficiências observadas em termos de sistemas de indicadores de desempenho deverão ser sanadas com a implementação de sistemas de informação de apoio ao controle gerencial, visando a direcionar mais eficazmente os esforços de melhoria nas empresas. 
As condições básicas para a implementação do ECR começam a se materializar. $\mathrm{O}$ alto percentual de empresas que afirmaram estar integrando as informações geradas pelos pontos de venda (PDV's) aos sistemas associados à emissão de pedido a fornecedores e ao controle de estoque, e que estão interligando-se com seus fornecedores via EDI, indica que passos importantes estão sendo dados no sentido da integração da cadeia de suprimento. Por outro lado, existem boas perspectivas para o relacionamento cooperativo entre o comércio e a indústria, segundo informações obtidas na pesquisa:

. ambas as partes reconhecem o EDI como fator importante para o desenvolvimento de parceria;

- existe o reconhecimento, tanto pelo comércio quanto pela indústria, da importância das parcerias no desenvolvimento dos programas ECR, quais sejam: sortimento de produtos nos pontos de venda, sistemas de ressuprimento, promoções e introdução de novos produtos;

. o relacionamento atual do comércio com seus fornecedores tende à cooperação;

. o nível de comunicação entre as partes no nível operacional acontece com razoável freqüência;

. têm havido mudanças organizacionais para a viabilização de parcerias.

\section{Conclusão}

Tanto o comércio quanto a indústria já despertaram para a importância do conceito de logística integrada. Alguns indicadores sobre esta conscientização já se fazem claros nesta pesquisa, notadamente nos aspectos relacionados a dimensão formalização:

- O nível hierárquico do principal executivo da logística, na maioria dos casos, se encontra no primeiro ou segundo escalão, com participação efetiva em decisões estratégicas das empresas.

. É substancial o percentual de empresas que indicam ter a missão logística formalizada e escrita, apesar do pequeno número de empresas que efetivamente desenvolvem o planejamento estratégico da logística.

- O controle sobre o sistema logístico, atualmente, não se restringe apenas às áreas tradicionais de armazenagem e transporte. Este controle já se está difundindo amplamente aos componentes logísticos de estoque, processamento de 
pedidos e compras/planejamento da produção (no caso das indústrias); no entanto o serviço ao cliente, em grande medida, ainda se encontra fora da área de influência da organização formal da logística nas empresas.

Por outro lado, quando avaliamos as dimensões monitoramento de desempenho e adoção de tecnologia de informação, verifica-se que muito ainda precisa ser feito, tanto para o comércio quanto para a indústria:

. Os níveis de insatisfação com os sistemas de indicadores são muito elevados, cerca de $30 \%$.

. Os níveis de insatisfação com softwares e hardwares encontram-se acima de $40 \%$.

Conforme se menciona na seção anterior, tais níveis de insatisfação são coerentes entre si, já que os sistemas de indicadores são gerados a partir de informações resultantes dos softwares e hardwares; mas, considerando a avaliação geral sobre o estágio de evolução da organização logística, a pesquisa aponta para evidências de que as empresas industriais são mais sofisticadas do que as comerciais, principalmente devido à dimensão relacionada à adoção de tecnologia: as empresas industriais estão mais desenvolvidas do que as comerciais no que se refere ao conteúdo tecnológico voltado às atividades logísticas.

Esse resultado confirma as expectativas geradas pelo modelo conceitual adotado, quais sejam: as empresas industriais, devido ao ambiente operacional mais complexo, desenvolveram maior nível de sofisticação da organização logística do que as empresas comerciais, com o objetivo de gerar maior nível de flexibilidade e tornar-se mais competitivas; as condições que envolvem as empresas industriais fazem com que o padrão de desenvolvimento da organização logística esteja mais avançado do que o padrão observado em empresas comerciais.

Sob a perspectiva da cadeia de suprimento, verifica-se que se por um lado a indústria apresenta maior conteúdo tecnológico do que o comércio, é este último que está puxando sua implementação: as exigências por melhores níveis de serviço e eficiência operacional, por parte do comércio, funcionam como fator motivador para um maior grau de adoção de tecnologia pela indústria. Este fato é corroborado pelos resultados obtidos na pesquisa: a indústria afirma que o poder de barganha na cadeia de suprimento reside no comércio, assim como reconhece no comércio a maior fonte de influência para a introdução de novas tecnologias de informação. Ainda assim, existe espaço para melhoria nesta dimensão, já que o nível de insatisfação encontrado é muito alto, acima de $40 \%$.

A análise geral realizada por meio de matrizes $2 \times 2$ demonstrou, de maneira esquemática, a aplicabilidade do modelo conceitual adotado para esta pesquisa, 
ou seja, as empresas industriais, por serem mais complexas, buscam maior nível de flexibilidade em suas operações que, por seu turno, é alcançado por meio de maior sofisticação da organização logística. Em suma, as perspectivas de desenvolvimento da organização logística na cadeia de suprimento de alimentos apontam para avanços no desenvolvimento de maior integração entre empresas industriais e comerciais.

\section{ReFERÉNCIAS BliblográficAs}

BOWERSOX, D. J.;

CLOSS, D. J.

Logistical management : the integrated supply chain process. New York : MacGraw-Hill, 1996.

BOWERSOX, D. J.;

DAUGHERTY, P. J.

Logistical excellence : it's not business as usual. Digital Press, 1992.

\section{BOWERSOX, D. J. et al.}

Leading edge logistics : competitive position for the 1990's. Oak Brook : Council of Logistics Management, 1989.

\section{ECR BRASIL.}

Resposta eficiente ao consumidor. Associação ECR Brasil, nov. 1998.

FLEURY, P. F.;

\section{LAVALLE, C. R.}

Avaliação do serviço de distribuição física : a relação entre a indústria de bens de consumo e o comércio atacadista e varejista.
Gestão e Produção, v. 4, n. 2, ago. 1997.

LAVALLE, C. R.

Evolução do serviço de distribuição física da indústria de bens de consumo na percepção do comércio varejista e atacadista. Revista Tecnologística, n. 36, nov. 1998.

SILVA, C. L.

$O$ estágio de desenvolvimento da organização logística em empresas brasileiras : estudo de casos. Rio de Janeiro, 1995. Dissertação (Mestrado em Administração) - Instituto de Pós-Graduação e Pesquisa em Administração, Universidade Federal do Rio de Janeiro.

STALK, G.;

EVANS, P.;

SCHULMAN, L. E.

Competing on capabilities : the new rules of coporate strategy. Harvard Business Review, v. 70, n. 2, p. 57-69, Mar./Apr. 1992. 
VAN AMSTEL, W. P.;

STARREVELD, D. W.

Does your company need a logistical executive? The International Journal of Logistics Management, v. 4, n. 1, p. 49-58, 1993. 